\title{
A INDIVIDUALIDADE NO ÂMBITO DA SOCIEDADE INDUSTRIAL
}

\author{
Isilda Campaner Palangana* \\ Lucélia Yumi Inumar"
}

\begin{abstract}
RESUMO. O presente estudo ocupa-se da autonomia individual na sociedade contemporânea. Investiga a possibilidade de constituição de um sujeito capaz de pensar e agir por si no interior das relações capitalistas. Conforme os escritos de autores clássicos como Karl Marx, Herbert Marcuse e Theodor Adorno, que analisam as transformações sociais na contemporaneidade, verifica-se que a industrialização, ao adentrar o processo produtivo, torna o trabalho uma atividade cada vez mais abstrata, estranha e alheia a quem a executa. Junto com o conhecimento desse processo, o sujeito perde o principal parâmetro de formação da individualidade. Vai sendo reduzido seu poder de controle sobre o próprio tempo e espaço, justamente o âmbito no qual poderiam ser cultivadas experiências outras que não as impostas pelas necessidades do mercado. Com base nos estudos efetuados, conclui-se que, na ordem capitalista, não há condições concretas favoráveis à formação de indivíduos autônomos.
\end{abstract}

Palavras-chave: individualidade, autonomia, sociedade industrial.

\section{INDIVIDUALITY IN THE INDUSTRIAL SOCIETY}

\begin{abstract}
This paper is about individual autonomy in contemporary society. It investigates the possibility of forming individuals capable of thinking and acting by themselves in the context of capitalist relationships. According to such classical writers as Karl Marx, Herbert Marcuse and Theodor Adorno, who have analysed social transformations in contemporary society, when industrialization transforms the productive process working becomes a more and more abstract, strange and alienating activity to those who execute it. The subject loses, then, both the perception of this process and the principal parameter for the formation of the individuality. The power to control their own time and space decreases in the milieus where they could possibly carry out different experiences from those imposed by the laws of the market. Research done demonstrates that there are not actual favourable circumstances for the formation of autonomous individuals.
\end{abstract}

Key words: individuality, autonomy, industrial society.

O presente estudo ocupa-se da autonomia individual na sociedade contemporânea. Investiga a possibilidade de constituição de um sujeito capaz de pensar e agir autônoma e criticamente no interior das relações sociais vigentes.

Apesar de o discurso burguês exaltar a liberdade, a emancipação do indivíduo, as reflexões que se seguem partem do pressuposto de que, com o advento da manufatura e, sobretudo, da industrialização, o trabalho torna-se uma atividade cada vez mais abstrata. O sujeito perde o conhecimento e o controle sobre o processo produtivo e, mais que isto, perde o controle sobre o próprio tempo e espaço. Nesse processo de alienação, as condições necessárias à formação da individualidade bem como da capacidade para auto-regular-se vão sendo reduzidas e padronizadas.

Ao contrário do que os fatos evidenciam, dissemina-se a idéia de supervalorização do sujeito. Os apelos à opinião, aos gostos, às necessidades, etc. de cada um, vindos principalmente dos meios de comunicação de massa, são constantes. Fica a

\footnotetext{
Professora Doutora do Departamento de Teoria e Prática da Educação da Universidade Estadual de Maringá.

\# Graduada em Pedagogia pela Universidade Estadual de Maringá.

Endereço para correspondência: Rua Francisco Glicério, 817 - Zona 07, Cep 87030-050, Maringá - PR. E-mail: yumiinumar@hotmail.com
} 
impressão de que o indivíduo nunca antes foi tão requisitado e respeitado. É justamente esta contradição que motiva e, acredita-se, justifica a análise aqui empreendida.

Primeiramente, convém retomar os conceitos de indivíduo e individualidade. Conforme definições contidas em dicionários, indivíduo significa “...ente complexo que forma um todo com existência peculiar e distinta (...). Diz-se particularmente de uma pessoa considerada singularmente em relação à espécie humana ou a um grupo de pessoas" (Aulete, 1985, p. 1954); "o exemplar de uma espécie qualquer, orgânica e inorgânica, que constitui uma unidade distinta" (Ferreira, 1986, p. 394); "pessoa considerada isoladamente em relação a uma coletividade" (Dicionário Brasileiro da Língua Portuguesa, 1976, p. 963). Individualidade, de acordo com essas mesmas fontes, é "o que constitui o indivíduo; o conjunto das qualidades que dentro da mesma espécie distinguem um ser de outro ser" (Aulete, 1985, p. 1954); "caráter especial, particularidade ou originalidade que distingue uma pessoa de coisa" (Ferreira, 1986, p. 394); "conjunto das qualidades que caracterizam um indivíduo" (Dicionário Brasileiro da Língua Portuguesa, 1976, p. 963).

É no trabalho, por intermédio das relações sociais estabelecidas nesse âmbito, que o indivíduo se forma e se transforma. A individualidade, quer dizer, a esfera da interioridade, só pode ser pensada na dimensão prática, no seio da exterioridade. Como escreve Crochik “...o indivíduo é produto da cultura, mas pela sua singularidade se diferencia dela" (1997, p. 13). Ou seja, a individualidade não é um conjunto de características que singularizam, gerado separadamente do social no interior do sujeito. Tais características constituem-se em unicidade com as condições socioculturais.

Do conceito de indivíduo depreende-se que a análise das possibilidades de existência do sujeito autônomo na atualidade pressupõe um conhecimento da sociedade contemporânea, isto é, da esfera na qual o pensamento é formado. Há que averiguar, nesse contexto, as condições objetivo/subjetivas para que tal formação ocorra.

\section{SOBRE AS CONDIÇÕES DE EXISTÊNCIA DO INDIVÍDUO AUTỔNOMO NA SOCIEDADE INDUSTRIAL}

O surgimento do trabalho é a primeira e fundamental condição para a existência do homem. É no e por meio do trabalho, das relações sociais de produção, que o indivíduo vai sendo constituído. A consciência só foi possível com a atividade prática. A produção de instrumentos de trabalho, que às vezes subentendia também a divisão natural do trabalho, por si só muda radicalmente a atividade do homem primitivo, distinguindo-a do comportamento animal. A formação de características e capacidades físicas e mentais do homem se dá pari passu ao uso e fabrico de instrumentos. As habilidades manuais não se fixam apenas nas mãos, mas também no pensamento. Os movimentos de trabalho requerem e provocam destrezas motoras e mentais. Na própria atividade social, esses movimentos ganham significado e vão sendo internalizados por aqueles que executam a atividade e por outros que os presenciam. O trabalho é a ação transformadora do homem sobre a natureza e, simultaneamente, sobre ele mesmo.

Nessa perspectiva, em que a relação entre homem e natureza é concebida de forma dialética, vislumbram-se um movimento de ação e outro de reação, pois o homem age sobre a natureza, modifica-a (ação) e, ao modificá-la, transforma-se a si próprio (reação) em termos de capacidades psicofísicas. O trabalho criou o homem e sendo este quem realiza o trabalho, então, o homem criou a si próprio (Marx, 1983). Desde o início, o trabalho é uma atividade social, que requer cooperação entre indivíduos, supondo uma divisão técnica dos afazeres.

$\mathrm{Na}$ modernidade, o trabalho passa por diferentes formas de organização, a saber: a manufatura, a fase da maquinaria e, posteriormente, na grande indústria, a automação rígida, até chegar à automação flexível. Em cada um desses períodos, verificam-se mudanças na forma do trabalho e no processo de produção. Tais transformações não ficam restritas ao campo do trabalho. Afetam, isto sim, a vida em sociedade, o que significa dizer todos os âmbitos da vida. Alteram hábitos, necessidades, valores, conceitos, habilidades físicas e intelectivas, enfim, o modo de ser.

Quando a ordem manufatureira começa a se estabelecer, em princípio, duas características a evidenciam. Uma delas refere-se ao agrupamento de diversos trabalhadores independentes, executores de ofícios variados, sob o controle de um mesmo capitalista. Para alcançar sua forma final, o produto passa pelas mãos de cada um desses artífices, que já não executam mais projetos concebidos individualmente. Devem, ao invés disso, adequar suas artes às necessidades e ao plano postos pelo dono tanto dos instrumentos de trabalho como do que dele advém. Antes

(...) uma carruagem era o produto global do trabalho de grande número de artífices independentes, tais como segeiro, seleiro, 
costureiro, serralheiro, correeiro, torneiro, passsamaneiro, vidraceiro, pintor, envernizador, dourador, etc. A manufatura de carruagens reúne todos esses diferentes artífices em uma casa de trabalho, onde eles trabalham simultaneamente em colaboração um com os outros (Marx, 1983, p. 267).

O artesão, agora encarregado de executar apenas uma parte da obra, perde, aos poucos, a habilidade para desempenhar o antigo ofício em toda sua dimensão. Originalmente, a manufatura de um produto, como a carruagem, por exemplo, consistia na "combinação de ofícios autônomos" (Marx, 1983, p. 267). Gradualmente, vai havendo uma divisão no processo produtivo. O unitário é decomposto em variadas "...operações particulares, cada operação cristaliza-se em função exclusiva de um trabalhador, e a sua totalidade é executada pela união desses trabalhadores parciais" (Marx, 1983, p. 267).

Uma outra característica que marca o surgimento da manufatura é o que Marx (1983) denomina de cooperação simples. Artífices que fabricam um mesmo produto ou algo da mesma espécie como papel, tipos de imprensa, agulhas, por exemplo, são tomados por um capitalista, passando a trabalhar numa mesma oficina. Assim, instaura-se um sistema de cooperação em que cada qual (com um ou dois auxiliares) fabrica o produto por completo, levando a cabo, consecutivamente, as distintas operações envolvidas na sua fabricação. $\mathrm{O}$ artífice prossegue trabalhando com base na antiga forma artesanal. Entretanto, a reunião de trabalhadores num mesmo lugar ea simultaneidade de seus trabalhos, em virtude de pressões externas, provocam uma reorganização no interior da fábrica. Para que, num prazo prescrito, se entregue uma quantidade maior de produtos, divide-se o trabalho. As operações são decompostas entre si e, depois, ordenadas no tempo e no espaço. Cada uma delas é entregue a um artífice individualmente e todas efetuadas simultaneamente pelos cooperadores, não sendo mais, portanto, o mesmo artífice o executor das diversas operações no interior de uma sucessão temporal.

Nessas condições, essa “...divisão acidental”, enfatiza Marx (1983), volta a ocorrer, expondo suas vantagens, tais como aumento da produção, economia de tempo e de materiais, configurando-se aos poucos na divisão sistemática do trabalho. Assim, "...do produto individual de um artífice autônomo, que faz muitas coisas, a mercadoria transforma-se no produto social de uma união de artífices, cada um dos quais realiza ininterruptamente uma mesma tarefa parcial" (Marx, 1983, p. 268).
Nota-se que, na manufatura, ocorre a separação das partes integrantes de uma atividade artesanal em suas variadas operações parciais. Não obstante, a execução mantém-se artesanal, a despeito de ser composta ou simples. Logo, está sujeita à força, habilidade, agilidade e firmeza do trabalhador individual na manipulação de sua ferramenta. Nesse sentido, a base produtiva e, concomitantemente, de formação, apesar de sofrer algumas mudanças, é mantida. $\mathrm{O}$ trabalhador ainda convive com o processo por inteiro. Logo, o referido processo - mesmo não estando mais sob seu domínio - é, para ele, concreto, visível, possível de ser apreendido. Contudo, com a divisão que a manufatura introduz no trabalho, o parâmetro de constituição individual começa a se distanciar do sujeito.

Ao analisar este período, Marx (1983) desvela a mutilação humana oriunda das alterações no trabalho. No início, a mesma ferramenta é utilizada na fabricação de diferentes produtos. É, pois, o instrumento que se adapta aos variados movimentos e planos de ação do trabalhador. Nessa condição, o objeto está subjugado ao sujeito, que dispõe de espaço para criar não apenas o produto, mas também seus instrumentos. Aos poucos, na manufatura, as ferramentas - acompanhando a divisão do trabalho vão sendo adaptadas a funções específicas; vão sendo simplificadas. Por essa via estabelece-se a materialidade que, de um lado, favorecerá o acúmulo de riquezas, facultando a existência da maquinaria; de outro, o aprofundamento da miséria física e espiritual, desencadeando um estado de jugo e degradação do ser humano que só se acentuará nos estágios seguintes do capitalismo.

Um trabalhador, que efetua uma única operação simplificada repetidas vezes durante uma vida inteira, tem seu corpo transformado em órgão automático dessa atividade. Exercendo-a mecanicamente, produz em menor tempo que o artífice, o qual realiza uma seqüência de atividades alternadamente. Comparado ao ofício autônomo, o mecanismo vivo da manufatura fabrica mais num tempo menor e também aumenta a força produtiva do trabalho, pois quanto mais se desagrega o todo, atribuindo as partes a diferentes trabalhadores, tanto mais se ganha em agilidade e perfeição, reduzindo-se, ainda, a perda de tempo.

Contraditoriamente, a divisão do trabalho tem aspectos positivos e negativos. De um lado, promove o desenvolvimento das forças produtivas; de outro, expropria os trabalhadores, favorecendo a acumulação de capital. O sujeito individual, treinado numa única função, fica impossibilitado de criar, de fazer além do que lhe é imposto. As forças intelectuais do processo 
material de produção, como propriedade alheia e poder que domina os indivíduos, resultam da divisão manufatureira do trabalho. Essa dissociação "...mutila o trabalhador transformando-o em trabalhador parcial" (Marx, 1983, p. 283). As mutilações do corpo e da mente não ficam restritas aos trabalhadores. Esses são apenas os portadores de um modo de agir, de pensar, de sentir que logo se espalha por toda a sociedade.

Consumido por uma função parcial, o indivíduo detém um conhecimento também parcial, desenvolve uma capacidade de compreensão limitada. Ele perde a competência para conceber e atuar no processo produtivo por completo. Dessa forma, juntamente com a objetividade, altera-se a subjetividade, quer dizer, o saber, o pensamento, o espaço de aprendizagem e o conteúdo aprendido. Ao alienar-se do domínio do processo de produção em sua totalidade, a consciência individual é privada da principal referência para o auto-reconhecimento; perde o parâmetro de formação da identidade individual. Assim, vê-se que, na manufatura, o acúmulo de capital e o aumento da força produtiva em sociedade equivalem ao empobrecimento material e espiritual do trabalhador tomado individualmente (Marx, 1983).

Nessas condições de trabalho, pensar e criar são competências desnecessárias. O que se requer são, tão somente, habilidades simples, quase sempre para movimentar o pé e/ou a mão. Não é sem razão que as manufaturas progridem mais onde se prescinde da consciência de si mesmo, de forma que "...a oficina pode ser considerada como uma máquina cujas partes são seres humanos" (Marx, 1983, p. 284).

Ante o exposto, cabe indagar: pode o sujeito desenvolver-se como indivíduo em um contexto que não lhe possibilita nem exige reflexão sobre o que faz e muito menos sobre si mesmo? onde não se cultiva a dúvida, o questionamento; onde não há espaço nem tempo para o exercício da criatividade, para a livre expressão? Como ser um indivíduo, único, singular, nesse contexto? $O$ que há é uma crescente padronização de hábitos, habilidades, gostos, comportamentos, idéias, em resumo, do modo de ser e de pensar.

Segundo A. Smith (conforme citado por Marx, 1983, p. 284)

(...) a inteligência da maior parte dos homens (...) desenvolve-se necessariamente a partir e por meio de suas ocupações diárias. Um homem que despende toda a sua vida na execução de algumas operações simples (...) não tem nenhuma oportunidade de exercitar sua inteligência. (...) Ele torna-se geralmente tão estúpido e ignorante quanto é possível a uma criatura humana.

Verifica-se, pois, que a deformação física e psíquica, a que os homens encontram-se expostos, está intimamente relacionada às divisões do trabalho e, por conseguinte, do conhecimento empreendidas pela sociedade capitalista.

Com o advento da maquinaria, gradativamente, o trabalhador, que antes manipulava somente uma ferramenta, é substituído pela máquina. Sua força de trabalho, sua propriedade maior, vai se tornando supérflua. Ao invés de manusear um instrumento, ele passa a comandar um mecanismo, que trabalha com uma grande quantidade de ferramentas iguais ou semelhantes de uma só vez. Aliás, muito mais que comandar, o trabalhador é comandado por esse complexo mecânico: a espécie de movimento, as habilidades e os hábitos requeridos, o ritmo da atividade são todos ditados pela máquina.

Apesar de o sujeito ser substituído pela máquina, as invenções mecânicas ainda não o livraram da labuta diária, nem a aliviaram, mesmo porque este não é, de forma alguma, o objetivo da maquinaria empregada pelo capital. Como explica Marx (1984), semelhante a qualquer outro desenvolvimento da força produtiva do trabalho, ela tem por finalidade baixar o preço da mercadoria e aumentar a obtenção da mais-valia.

Nesse contexto de produção, o indivíduo deve adaptar-se ao movimento invariável e contínuo da máquina. Assim, “...da especialidade por toda a vida em manejar uma ferramenta parcial surge, agora, a especialidade por toda a vida em servir a uma máquina parcial" (Marx, 1984, p. 43). O trabalhador é convertido em um apêndice do processo produtivo. Observa-se que na manufatura e no artesanato, o trabalhador dispõe de ferramentas e, na fábrica, ele dispõe-se à máquina. No primeiro, é o trabalhador que executa e impõe o movimento e o ritmo ao meio de trabalho, já no segundo, é necessário que ele se ajuste e acompanhe a ambos. $\mathrm{Na}$ manufatura, os trabalhadores fazem parte de um mecanismo vivo. $\mathrm{Na}$ fábrica, tem-se um mecanismo morto, que independe do operário e ao qual ele é admitido como suplemento vivo.

O trabalhador, na qualidade de apêndice que serve à máquina, é submetido a uma rotina de inacabável tortura, onde a exaustiva repetição termina em estafa, apatia e outros tantos problemas de saúde.

Enquanto o trabalho em máquinas agride o sistema nervoso ao máximo, ele reprime o jogo polivalente dos músculos e confisca toda a livre atividade corpórea e espiritual. 
Mesmo a facilitação do trabalho torna-se um meio de tortura, já que a máquina não livra o trabalhador do trabalho, de seu trabalho de conteúdo. Toda produção capitalista, à medida que ela não é apenas processo de trabalho, mas ao mesmo tempo processo de valorização do capital, tem em comum o fato de que não é o trabalhador quem usa as condições de trabalho, mas, que pelo contrário, são as condições de trabalho que usam o trabalhador: só, porém, com a maquinaria é que essa inversão ganha realidade tecnicamente palpável. Mediante sua transformação em autômato, o próprio meio de trabalho se confronta, durante o processo de trabalho, com o trabalhador como capital, como trabalho morto que domina e suga a força de trabalho viva(...) (Marx, 1984, p. 43-44).

A produção fabril, na busca por um produto mais barato e preocupada em satisfazer as demandas do capital investido, bem como as necessidades crescentes dos consumidores, inicialmente estabeleceu um sistema que prescrevia uma maior rentabilidade, derivada da maior divisão de operações. Adotando a automação rígida, ou seja, um sistema de esteira automática com postos de tarefas fixos, a indústria aumenta a escala de produção, agilizando seu processo. Com isso, tal sistema alcança uma perfeição contraditória: “...incorpora os tempos e os movimentos no maquinismo; fragmenta os gestos demandados do trabalho vivo; energiza a produção e aprofunda a submissão do processo de trabalho ao capital" (Palangana, 1998, p. 63).

Nesse sistema de produção, o trabalhador é forçado a manter-se curvado e atento ao seu trabalho, sem atrapalhar o exercício das ocupações de seus companheiros. Dessa forma, executando operações parciais na fabricação de um produto, com gestos que se repetem incansavelmente, o trabalhador torna-se emburrecido, prevalecendo nele o sentimento de insatisfação. Não tendo contato com o produto finalizado, ele não pode mais avaliar a qualidade de seu serviço, tampouco estipular-lhe valor comercial. Assim, a despersonalização do trabalho é acompanhada

‘(..) pela consciência de não poder jamais acabar uma tarefa, de jamais poder, dando um recuo, dizer a si próprio que realizou alguma coisa, por si mesmo, e que a fez bem feita'. Um trabalho inacabado é desprovido de significação, sobretudo, para quem não o conclui (Palangana, 1998, p. 61).
O que importa é a resistência física e psíquica do operário e nada mais. Nessas condições de trabalho, ao invés de o homem realizar-se como ser humano, ele se desumaniza.

A implantação da automação rígida acumula riquezas sociais e provoca sérios danos ao indivíduo, acabando em prejuízos e, portanto, em preocupação para o capital. O desgaste físico e psíquico do sujeito - por se manter num mesmo lugar de trabalho todos os dias, realizando a mesma tarefa limitada e limitante é tão grande que são feitas adaptações incessantes entre operários e postos de trabalho. Os movimentos operários obrigam os patrões a constantes acordos. Neste contexto, o enfado, o desprazer, a apatia, o absenteísmo vão aumentando. As faltas ao trabalho tornam-se insustentáveis, devido também aos prejuízos que causam. Quanto mais se segmentam as operações, mais cresce a monotonia.

Depois da Primeira Guerra, o repúdio pela ortodoxia do trabalho parcelado chega a níveis preocupantes. $\mathrm{O}$ desgaste do trabalhador, pela permanência em um mesmo posto de trabalho, é tão grande que a indústria se vê obrigada a ajustes constantes. A divisão extremada do trabalho e, por conseguinte, o aumento da vigilância, do controle, provocam tensão $\mathrm{e}$ protesto por parte dos trabalhadores. A sociedade burguesa descobre o limite da capacidade do homem para suportar a degradação, o sofrimento, a despersonalização, sem prejuízo do seu desempenho (Harvey, 1992).

Para atender pedidos pequenos, devido ao rastro de descaptalização deixado pelas duas Guerras Mundiais, com o intuito de resolver as crises advindas da produção rígida e enfrentar as desavenças com os trabalhadores, o capital articula mudanças no conteúdo e na forma do trabalho. A produção em grandes séries homogêneas vai sendo substituída pela especialização flexível, respaldada por um expressivo desenvolvimento tecnológico em que a microeletrônica é a grande alavanca desse salto dado pela sociedade industrial. Nasce a automação flexível, que se fundamenta na produção existente e, ao mesmo tempo, rompe com os limites da mesma.

O trabalho vai sendo informatizado e, nessa medida, automatizado. Por meio de um botão, o sujeito agora opera várias máquinas, comandos e circuitos ao mesmo tempo. O computador passa a ser o instrumento de trabalho para boa parte daqueles que conseguem se manter empregados. As tarefas, antes fragmentadas ao extremo, vão sendo reintegradas de acordo com suas especificidades. $\mathrm{O}$ trabalho automatizado, flexível e integrado requer novas capacidades do trabalhador; porém todas elas 
desenvolvidas dentro dos marcos definidos pelas necessidades do mercado. Observe-se que, nessa ambiência, o indivíduo continua não tendo nem espaço nem tempo para se realizar como tal.

Referindo-se ao período de transição da automação rígida à flexível, Harvey (1992, p. 303-5) assim o sintetiza: o fordismo demanda e, ao mesmo tempo propicia

...capital fixo na produção em massa,
mercados estáveis, padronizados e
homogêneos, uma configuração fixa de
influência e poder político-econômicos, uma
autoridade e metateorias facilmente
identificáveis, um sólido alicerce na
materialidade e na racionalidade técnico-
científica (...). A produção flexível, por seu
turno, é dominada pela ficção, pela fantasia,
pelo imaterial (particularmente do dinheiro),
pelo capital fictício, pelas imagens, pela
efemiridade, pelo acaso e pela flexibilidade
em técnicas de produção, mercados de
trabalho e nichos de consumo.

Juntamente com a reconversão produtiva, propaga-se a idéia de que o trabalho repetitivo, ultrasimples, desmotivante e embrutecedor estaria desaparecendo. Será que tal proferição se sustenta na prática?

\begin{abstract}
Nas indústrias automatizadas, em lugar de energia física, requer-se do trabalhador habilidades técnicas e mentais: '....aptidões da cabeça mais do que das mãos; do lógico mais do que do artífice; dos nervos mais do que dos músculos; do piloto mais do que do trabalhador braçal; do técnico de manutenção mais do que do operador' (Palangana, 1998, p. 119).
\end{abstract}

Nota-se um apelo às capacidades intelectuais que, no entanto, permanecem sendo formadas e orientadas a partir de necessidades alheias ao próprio indivíduo. A invasão e domínio deste campo pela lógica da sociedade industrial prosseguem mais fortes que nunca. Mantida intacta a relação de compra e venda da força de trabalho, a mecanização e, posteriormente, a eletronização do processo produtivo, apenas intensificaram a escravidão humana, que antes era preferencialmente física e, agora, é física e mental. Forma-se um grupo numericamente pequeno e seleto de homens considerados qualificados - por disporem de uma formação especializada, marcadamente técnica. Contudo, esta "alta" qualificação não os torna aptos a compreender e encaminhar problemas numa ótica diferente da estabelecida. Uma qualificação cujo trabalho consiste em vigiar painéis de controle, em verificar se tudo está funcionando normalmente, não pode proporcionar autonomia intelectual ao indivíduo. Nela não se encontram elementos imprescindíveis à referida formação, dentre os quais se destacam: conteúdo e domínio do tempo e espaço, e condições de apreensão do objeto para si.

É ilusório o pensamento segundo o qual com a automação flexível superar-se-ia a alienação do trabalho inerente à acumulação de corte taylorista/fordista. Como dito anteriormente, tais alterações não eliminam o caráter abstrato do trabalho, não conciliam concepção e produção, não devolvem ao trabalhador o conhecimento do processo produtivo por completo, muito menos a autonomia sobre o objeto para criá-lo e recriá-lo.

Ao padronizar o produto, as máquinas padronizam o próprio ser humano.

O tamanho, o formato, a consciência, a durabilidade, em resumo, as características do produto são tanto quanto possível, padronizadas, exibindo poucas variações de um modelo para outro. Com a produção em massa, não é mais o objeto - como o sapato, a roupa, a máquina, etc. - que se adequa ao indivíduo, é, ao contrário, o indivíduo que se adequa ao objeto. A uniformidade está na produção e nas relações sociais, isto é, nas condições de existência. O ritmo de vida (até o caminhar), os hábitos (como os de vestuário, alimentação, lazer, etc.), as habilidades cultuadas, o pensamento, crenças, valores, os afazeres diários estão, todos eles, em conformidade (Palangana, 1998, p. 61).

Nada foge ao controle capitalista. A sociedade atual, além do modo de produção e consumo, dispõe dos meios de comunicação e do sistema educativo para formar com vistas à padronização e à adaptação. Pactuando com Santos (1995, p. 206), “... a naturalização dos indivíduos é o fundamento da igualdade formal dos cidadãos. (...) Concebido de modo abstrato, os indivíduos são fungíveis, recipientes indiferenciados de uma categoria universal". Dessa análise depreende-se que se a esfera do trabalho não é um ambiente de realização da individualidade, fora dele também não o é. Nada é modificado, senão para atender a necessidades do mercado. E, o trabalho que se afasta desse fim não garante a sobrevivência de quem o executa.

A maior aceleração no tempo de giro do capital, na venda, no consumo e, simultaneamente, no tempo para a vida se deve à reorganização empreendida no 
processo produtivo. Para permitir maior velocidade na circulação da mercadoria, aprimoram-se o sistema de comunicação, o de controle e as técnicas de distribuição do produto minuciosamente inspecionado. Num ritmo desnorteador e estonteante para o indivíduo, o consumo é acelerado no movimento de mercados de massa que dão cabo a objetos e serviços supérfluos, apresentados pela mídia, como de primeira necessidade. Pois bem, a afirmação da individualidade, escreve Harvey (1992) depende de lugar, de uma referência concreta, tem de apoiar-se em algum ponto do poder motivacional da tradição. Mas, como manter o sentido de continuidade histórica diante do fluxo de efemiridades da acumulação flexível?

O gerador central, que define a forma e o ritmo da esfera espaço/tempo para a vida, é o espaço/tempo da produção. Desse modo, se autonomia é a faculdade de estruturar, de delimitar o próprio tempo e o próprio espaço, como postula Rebecchi (1936/1990), há muito o sujeito a perdeu, visto que estas duas propriedades, em princípio, do sujeito são apropriadas, administradas e exploradas pelo mercado em seu proveito. Como bem demonstra Harvey (1992), a manutenção da hegemonia político-econômica depende da capacidade do capital para controlar a base material - e daí também a subjetiva - da atividade humana.

$\mathrm{Na}$ luta por manter o sistema vigente, a sociedade caracteriza-se cada vez mais como uma sociedade de coisas descartáveis, com processo de trabalho e produtos dominantemente voláteis e efêmeros. $\mathrm{Na}$ área dos descartáveis estão englobados “...desde copos, talheres, guardanapos, embalagens, material de higiene até conceitos, valores, formas de relacionamento, estilos de vida, etc. Com o lixo, descartam-se modos de pensar e de ser" (Palangana, 1998, p. 137). O indivíduo é forçado a lidar com o desuso quase momentâneo, tendo que aprender a se reajustar constantemente e com agilidade a fins particulares, do capital, porém, apresentados como sendo sociais. Os campos do gosto, da vontade, do desejo, dos conceitos - especialmente, dos conceitos de bom e belo -, são comandados pelo mercado, que os manipula a fim de instigar o consumo.

Os motivos que justificam a (ir)racionalidade consumista não estão ao alcance da consciência individual. Constata-se que, a experiência formativa, da qual fala Adorno (1971/1995), vai sendo minada pela forma como se organiza e se realiza o trabalho. Com ela desaparece a capacidade de reflexão, de análise, o locus privilegiado de individualização.
Os indivíduos executam funções codificadas, concebidas num plano externo e alheio a eles. $\mathrm{O}$ sucesso material da produção deixa os homens maravilhados, a ponto de não perceberem o domínio do poder impessoal a que se encontram subjugados. Disciplinada para satisfazer necessidades que lhe são estranhas, para executar um trabalho que se tornou abstrato, a consciência é incapaz de resguardar a si mesma, de ter objetivos próprios, de calcular com base numa linha de raciocínio que não seja a dominante.

O indivíduo já não mais se reconhece nessa ambiência, nessa sociedade do aparente. Colocando à disposição e levando ao consumo uma parafernália em favor da beleza e da boa forma, o mercado explora esse veio ao máximo - principalmente por intermédio da comunicação de massa -, como pode ser visto no consumo de produtos que englobam massagens, ginásticas, natação, musculação e muitos outros exercícios físicos que crescem a cada dia. A aparência física nunca antes foi tão valorizada. Tanto que, para a maioria dos empregos, além da qualificação é preciso ter boa aparência.

Isto posto, é possível perceber que as chances de o indivíduo desenvolver-se em todos os sentidos nesta sociedade, são praticamente nulas. Os hábitos, o pensamento, as habilidades, os padrões de comportamento, os desejos, etc. do indivíduo são manipulados por necessidades e interesses externos a ele, não havendo condições objetivas para que o indivíduo possa agir, pensar, criar, etc., por livre e espontânea vontade, que dizer, independentemente de necessidades e critérios impostos por outrem.

À guisa de conclusão, pode-se dizer que a sociedade capitalista transforma-se ao longo de sua história. E, nesse processo, vai cercando o indivíduo e moldando-o a seu modo. Com base em funções parcializadas e movimentos repetitivos durante um longo tempo, o trabalho fragmenta o conhecimento, mecaniza as habilidades físicas e, mais tarde, coopta, além das habilidades físicas, também as mentais. Assim, sob o controle das relações capitalistas, o indivíduo é subjugado ao tempo-espaço da produção que, visando a satisfazer necessidades do consumo, aniquila as condições propícias à formação da individualidade, da consciência emancipada. A tecnologia é consumida não no sentido do homem, mas no sentido do capital. E, especialmente balizada pelos meios de comunicação de massa, contribui para o estabelecimento de padrões de julgamento, hábitos, atitudes, etc., isto é, para que a ordem estabelecida se mantenha.

Assim, 
...a autonomia da razão perde seu significado na mesma medida em que os pensamentos, sentimentos e ações dos homens são moldados pelas exigências técnicas do aparato por eles mesmo criado. A razão encontrou seu túmulo no sistema de controle, produção e consumo padronizados. Neste lugar, ela reina através das leis e mecanismos que garantem a eficácia, a eficiência e a coerência do sistema (Marcuse, 1997, p. 122).

O desenvolvimento das forças produtivas é mais que suficiente para liberar o homem da labuta, do trabalho que escraviza. Tecnologicamente falando, a sociedade industrial está apta a conceder ao homem tempo e espaço para que o mesmo se firme como indivíduo, para que experiencie a autonomia de pensamento e ação. A despeito disso, as relações produtivas mantêm-se e, com elas, um indivíduo subjugado física e mentalmente.

\section{BIBLIOGRAFIA}

Adorno, T. W. (1995). Educação e Emancipação. (W. L. Maar, Trad.) São Paulo: Paz e Terra. (Trabalho original publicado em 1971)

Aulete, C. (1985). Dicionário Contemporâneo da Língua Portuguesa. ( $4^{\mathrm{a}}$ ed.). Rio de Janeiro: Delta.
Crochik, J. L. (1997). Preconceito: Indivíduo e Cultura. $\left(2^{\mathrm{a}}\right.$ ed.). São Paulo: Robe.

Dicionário Brasileiro da Língua Portuguesa. (1976). (2 $2^{\mathrm{a} .}$ ed.). São Paulo: Encyclopaedia Britannica do Brasil. Mirador Internacional.

Ferreira, A. B. de H. (1986). Novo Dicionário da Língua Portuguesa. ( $2^{\mathrm{a}}$ ed., rev. e am.). Rio de Janeiro: Nova Fronteira.

Harvey, D. (1992). Condição Pós-Moderna. São Paulo: Loyola.

Marcuse, Herbert. Algumas Implicações Sociais da Tecnologia Moderna. (1997). Praga: Revista de Estudos Marxistas 1 , 113-140.

Marx, K. (1983). O Capital: Crítica da Economia Política. São Paulo: Abril Cultural, Tomo 1.

Marx, K. (1984). O Capital: Crítica da Economia Política. São Paulo: Abril Cultural, Tomo 2.

Palangana, I. C. (1998) Individualidade: Afirmação e Negação na Sociedade Capitalista. São Paulo: EDUC/Plexus.

Rebecchi, E. (1990). O Sujeito Frente à Inovação Tecnológica. (R. Fillippis, Trad.) Petrópolis: Vozes. (Trabalho original publicado em 1936)

Santos, B. de S. (1995). Pela Mão de Alice: O Social e o Político na Pós-Modernidade. Porto: Afrontamento.

Recebido em 28/07/2000

Revisado em 20/09/2001

Aceito em 30/09/2001 